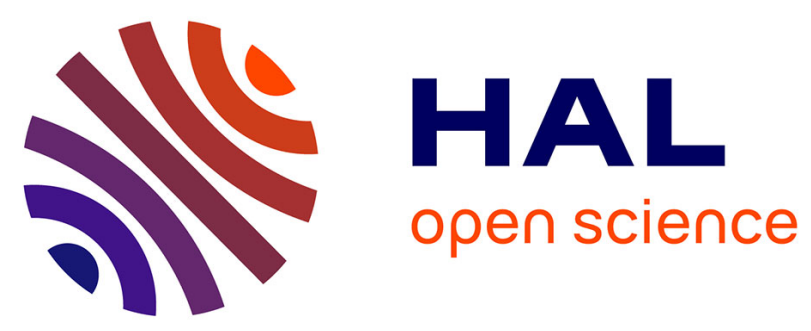

\title{
Structure of a [2Fe-2S] ferredoxin from Rhodobacter capsulatus likely involved in Fe-S cluster biogenesis and conformational changes observed upon reduction
}

Germaine Sainz, Jean Jakoncic, Larry C. Sieker, V. Stojanoff, N. Sanishvili, Marcel Asso, Patrick Bertrand, J. Armengaud, Yves Jouanneau

\section{To cite this version:}

Germaine Sainz, Jean Jakoncic, Larry C. Sieker, V. Stojanoff, N. Sanishvili, et al.. Structure of a [2Fe-2S] ferredoxin from Rhodobacter capsulatus likely involved in $\mathrm{Fe}-\mathrm{S}$ cluster biogenesis and conformational changes observed upon reduction. Journal of Biological Inorganic Chemistry, 2006, 11, pp.235-246. hal-00378370

\section{HAL Id: hal-00378370 https://hal.science/hal-00378370}

Submitted on 24 Apr 2009

HAL is a multi-disciplinary open access archive for the deposit and dissemination of scientific research documents, whether they are published or not. The documents may come from teaching and research institutions in France or abroad, or from public or private research centers.
L'archive ouverte pluridisciplinaire HAL, est destinée au dépôt et à la diffusion de documents scientifiques de niveau recherche, publiés ou non, émanant des établissements d'enseignement et de recherche français ou étrangers, des laboratoires publics ou privés. 
1 Structure of a [2Fe-2S] ferredoxin from Rhodobacter capsulatus likely involved in Fe-S

4 Germaine Sainz $^{1 \dagger}$ Jean Jakoncic ${ }^{1,2 \dagger}$, Larry C. Sieker ${ }^{3}$, Vivian Stojanoff ${ }^{1,2}$, Nukri Sanishvili ${ }^{4}$, 5 Marcel Asso $^{5}$, Patrick Bertrand ${ }^{5}$, Jean Armengaud ${ }^{6,7}$ and Yves Jouanneau ${ }^{6 凶}$

European Synchrotron Radiation Facility, BP 220, 38054 Grenoble Cedex 9, France, and

National Synchrotron Light Source, Upton, NY 11973, USA, and Structural Biology

9 Center/Midwest Center for Structural Genomics, Argonne National Laboratory, IL 60439,

10 USA and Laboratoire de Bioénergétique et Ingénierie des Protéines, UPR 9036 CNRS, 13402

Marseille Cedex 20, France, and Laboratoire de Biochimie et Biophysique des Systèmes Intégrés, CNRS UMR 5092, Département Réponse et Dynamique Cellulaires, CEA-Grenoble, F-38054 Grenoble Cedex 9, France, and CEA-Valrho, DSV-DIEP-SBTN, BP 171, F-30207 Bagnols-sur-Cèze cedex, France.

${ }^{\circledR}$ Corresponding author : CEA- Grenoble, 38054 Grenoble Cedex 9, France. E-mail :

yves.jouanneau@cea.fr. Phone : 33 (0)4.3878.4310 ; Fax : 33 (0)4.3878 5185.

${ }^{1}$ European Synchrotron Radiation Facility, Grenoble.

$22{ }^{2}$ Current address: Brookhaven National Laboratory, National Synchrotron Light Source, NY

$23{ }^{3}$ Current address: Department of Biological Structure, University of Washington, Seattle, WA

$24{ }^{4}$ Structural Biology Center, Argonne National Laboratory.

$25{ }^{5}$ Laboratoire de Bioénergétique et Ingénierie des Protéines, Marseille

$26{ }^{6}$ Laboratoire de Biochimie et Biophysique des Systèmes Intégrés, Grenoble

${ }^{7}$ CEA-Valrho, DSV-DIEP-SBTN, BP 171, F-30207 Bagnols-sur-Cèze cedex, France.

${ }^{\dagger}$ these authors contributed equally to this work

Running title: Structure of a [2Fe-2S]ferredoxin from $R$. capsulatus

Number of figures: 8

Number of tables: 3 
2 ABBREVIATIONS

3

4 Adx, adrenodoxin;

5 AnFd, Anabaena PCC7119 ferredoxin;

6 Fd, ferredoxin;

7 Fdx, ferredoxin from E. coli;

8 MAD, multiple anomalous dispersion;

$9 \mathrm{mr}$, molecular replacement;

10 Pdx, putidaredoxin;

11 rms, root means square

12 


\section{Abstract}

2 FdVI from Rhodobacter capsulatus is structurally related to a group of [2Fe-2S] ferredoxins

3 involved in iron-sulfur cluster biosynthesis. Comparative genomics suggested that FdVI and

4 orthologs found in $\alpha$-proteobacteria are involved in this process. Here, the crystal structure of

$5 \quad$ FdVI has been determined on both the oxidized and the reduced protein. The [2Fe-2S] cluster

6 lies $6 \AA$ below the protein surface in an hydrophobic pocket without access to the solvent.

7 This particular cluster environment might explain why the FdVI midpoint redox potential (-

$8306 \mathrm{mV}$ at $\mathrm{pH}$ 8.0) did not show temperature or ionic strength dependence. Besides the four

9 cysteines that bind the cluster, FdVI features an extra cysteine which is located close to the S1

10 atom of the cluster and is oriented in a position such that its thiol group points towards the

11 solvent. Upon reduction, the general fold of the polypeptide chain was almost unchanged. The

12 [2Fe-2S] cluster underwent a conformational change from a planar to a distorted lozenge. In

13 the vicinity of the cluster, the side chain of Met24 was rotated by $180^{\circ}$ bringing its $\mathrm{S}$ atom

14 within H-bonding distance of the $\mathrm{S} 2$ atom of the cluster. The reduced molecule also featured a

15 higher content of bound water molecules, and more extensive hydrogen bonding networks

16 compared to the oxidized molecule. The unique conformational changes observed in FdVI

17 upon reduction are discussed in the light of structural studies performed on related

18 ferredoxins.

19 Key words : ferredoxin; crystal structure; iron sulfur cluster; redox potential; conformational 20 changes; 
3 Ferredoxins are small electron carrier proteins that participate in various redox reactions, and

4 are widely distributed among all forms of living organisms. Soluble ferredoxins containing 5 one $[2 \mathrm{Fe}-2 \mathrm{~S}]$ cluster comprise two major groups, the plant-type and the vertebrate-type

6 ferredoxins, which exhibit distinctive biochemical and structural properties [1,2]. Vertebrate-

7 type ferredoxins are exemplified by adrenodoxin which is involved in steroid hormone

8 biosynthesis in mammals [3]. Adrenodoxin serves as an electron donor to two types of

9 cytochrome P450 enzymes present in mitochondria of the adrenal cortex. Vertebrate

10 ferredoxins have homologous counterparts in bacteria, some of which are functionally

11 associated with P450 enzymes [4,5].

12 Over the past five years, information available from the sequencing of complete genomes

13 showed that vertebrate-type ferredoxins are present in almost all living cells except in 14 Archaea, suggesting that they might fulfill a more general function. Studies on prokaryotes belonging to the $\gamma$-Proteobacteria, including Azotobacter vinelandii, Escherichia coli and Haemophilus influenzae, provided evidence that certain vertebrate-type ferredoxins are responsible together with the $i s c S$, isc $U$, iscA, $h s c B$ and $h s c A$ gene products for the formation and insertion of Fe-S clusters in proteins [6,7]. Likewise, the mitochondrial ferredoxin Yah1 from Saccharomyces cerevisiae was shown to be essential for the biogenesis of iron-sulfur proteins in yeast [8]. Although vertebrate-type ferredoxins fulfill very diverse functions 21 depending on the original host cells, sequence alignment highlighted several conserved 22 features including the cluster-binding sequence, Cys- $\mathrm{X}_{5}-\mathrm{Cys}-\mathrm{X}-\mathrm{Thr}-\mathrm{Cys}-\mathrm{X}_{36-38}$-Cys [9].

23 The crystal structure of a truncated form of a typical vertebrate ferredoxin, bovine 24 adrenodoxin, has been described [10] and a detailed structure-function analysis of 25 adrenodoxin has been published by Grinberg and co-workers [9]. More recently, the X-ray 
1 structures of putidaredoxin and the related bacterial ferredoxin from E. coli (Fdx) have been

2 reported [11,12]. Although amino acid sequence comparisons showed only limited identities

3 (e.g., 33\% between adrenodoxin and putidaredoxin ), the structures of these proteins are very

4 similar, especially in the core domain which contains the cluster $[10,12]$.

5 In this report, we describe the X-ray structure of FdVI, a ferredoxin from the photosynthetic

6 bacterium Rhodobacter capsulatus ( $\alpha$-Proteobacteria). $R$. capsulatus synthesizes six

7 ferredoxins, three of which were found to contain a [2Fe-2S] cluster. Two ferredoxins,

8 designated FdIV and FdV, belong to the plant-type ferredoxin subgroup and are involved in

9 nitrogen fixation [13,14] while FdVI is related to the vertebrate category [15]. Genetic studies

10 indicated that FdVI must play an essential role since disruption of its structural gene $f d x E$ is

11 lethal [16]. In a previous study, FdVI was overproduced in E. coli, allowing the recombinant

12 ferredoxin to be purified and crystallized [17]. Here, the crystal structure of FdVI was

13 determined from X-ray diffraction data collected in the oxidized and partially reduced states,

14 allowing a description at $2.0 \AA$ resolution of structural changes occurring upon reduction. The

15 significance of the redox-induced conformational changes observed in FdVI are discussed in

16 the light of previous studies describing redox changes in related ferredoxins. 
3 Purification and crystallization of FdVI. The purification and crystallization conditions of

$4 \quad$ FdVI have been described previously [17]. Diffraction quality crystals were obtained in two

steps by vapor equilibration. In the first step seed crystals were grown by the hanging drop method. Crystallization was performed with a $10 \mathrm{mg} / \mathrm{ml}$ protein solution buffered with 100 $\mathrm{mM}$ imidazole ( $\mathrm{pH}$ 7.6) plus sodium formate to make the drop initially 5.4 M. The drop was then equilibrated against a solution of 7.0 M sodium formate containing $100 \mathrm{mM}$ imidazole (pH 7.6) at $15{ }^{\circ} \mathrm{C}$. In a second step, the seed crystals were washed briefly in imidazole buffered 3.5-4.2 $\mathrm{M}$ formate and grown in a sitting drop as long red-brown prismatic shaped needles, $0.4 \mathrm{~mm} \times 0.1 \mathrm{~mm} \times 0.05 \mathrm{~mm}$ in size, within $2-3$ days. These crystals were sensitive to changes in temperature and were lost when exposed to temperatures above $20^{\circ} \mathrm{C}$. The crystals were cryoprotected by a quick soak in $13 \%$ glycerol and flash-frozen at $100 \mathrm{~K}$ in a cold $\mathrm{N}_{2}$ stream generated by an Oxford Cryosystems apparatus.

Reduction of FdVI crystals. The following experiments were carried out in a glove box under anoxic conditions $\left(<2 \mathrm{ppm} \mathrm{O}_{2}\right)$. Two different ways of producing crystals of reduced FdVI have been implemented : either crystallization of the reduced protein, or soaking crystals of the oxidized protein in a reducing solution. The former was performed in formateimidazole solution as described above except that $2 \mathrm{mM}$ sodium dithionite (Fluka) was added to both the protein sample and the crystallization solution. The formate concentration was varied between 5 and $7 \mathrm{M}$ at $\mathrm{pH}$ values of 7.6 and 7.8. Alternatively, oxidized crystals were soaked in a reducing solution consisting of the mother solution containing a slight excess of precipitant (7.3 M formate) and a variable concentration of dithionite. Reduced crystals were obtained after two successive soaks in 20 and $30 \mathrm{mM}$ dithionite for $20 \mathrm{~min}$ each. The extent of reduction of the protein in the crystals was assessed by micro-spectrophotometry as 
1 described below. Reduced crystals were soaked in $13 \%$ glycerol and flash-frozen in liquid

2 propane inside the glove box.

4 Analytical and spectroscopic methods. The concentration of $R$. capsulatus FdVI was

5 determined from absorbance measurements at $416 \mathrm{~nm}$ using an absorption coefficient of 10

$6 \mathrm{mM}^{-1} \mathrm{~cm}^{-1}$. Ultraviolet-visible absorption, EPR and circular dichroïsm spectroscopy were

7 performed according to published procedures [13]. Micro-spectrophotometric analysis of

8 FdVI crystals was carried out with a Cryobench apparatus allowing measurements with a thin

9 light beam which was delivered through optical fibers[18] .

10

11 Determination of midpoint redox potentials. Redox titrations of $R$. capsulatus FdVI and

Spirulina maxima ferredoxin were carried out at room temperature under argon in Tris- $\mathrm{HCl}$, pH 8.0 buffer containing $42 \mu \mathrm{M}$ protein. The purification of the sample of S. maxima ferredoxin used in this study has been described previously [19]. The reduction of the protein was monitored by recording absorbance changes at 456 and $430 \mathrm{~nm}$ for FdVI and S. maxima ferredoxin, respectively. Redox potentials were adjusted by stepwise additions of $10 \mathrm{mM}$ sodium dithionite and were measured with a combined $\mathrm{Pt}-\mathrm{Ag} / \mathrm{AgCl} / \mathrm{KCl}(3 \mathrm{M})$ microelectrode. Equilibrium with the electrode was achieved by adding the following mediators: phenosafranin $(-255 \mathrm{mV})$, benzyl viologen $(-350 \mathrm{mV})$ and methyl viologen $(-440 \mathrm{mV})$, each at $2 \mu \mathrm{M}$ concentration. The absorption of the mediators at $456 \mathrm{~nm}$ was negligible. Redox titrations were performed at two different ionic strengths: $0.1 \mathrm{M}$ and $1 \mathrm{M} \mathrm{NaCl}$. A nonisothermal potentiometric device was used in temperature-dependent experiments. An optical cell containing the protein solution, a platinum Metrohm microelectrode and a calibrated thermocouple was placed in a variable temperature holder and the reference electrode was kept at $23^{\circ} \mathrm{C}$. Under these conditions, the temperature coefficient $\mathrm{dE}^{\circ 1} / \mathrm{dT}$ of the midpoint 
1 potential $E^{o^{\prime}}$ is directly proportional to the entropy variation $\Delta S_{\mathrm{rc}}^{\gamma^{\prime}}=S_{\text {red }}^{\gamma^{\prime}}-S_{o x}^{\gamma^{\prime}}$ of the studied 2 redox couple [20]. All potential values are given with respect to the standard hydrogen 3 electrode.

5 X-ray data collection and processing. Diffraction data were collected on both oxidized and 6 reduced crystals. Initially, a MAD experiment at the iron absorption edge was carried out on 7 two crystals of oxidized FdVI. From the first crystal, a fluorescence scan was recorded. The f' 8 and f" values were calculated and plotted as a function of energy with the program $\mathrm{CHOOCH}$ 9 [21]. From this plot, the inflection point and the peak of absorption were determined to be at 7.1198 KeV and 7.1315 KeV in energy, equivalent to $1.7414 \AA$ and $1.7386 \AA$ in wavelength, 11 respectively. The high energy remote was chosen at $8 \mathrm{KeV}$ (wavelength $\lambda=1.5498 \AA$ ). X-ray diffraction data were recorded using a 3 x 3 mosaic CCD detector on the undulator beam line 13 ID19 at the Advanced Photon Source (Argone National Laboratory, IL) [22]. A $180^{\circ}$ data set was collected at each wavelength with $2^{\circ}$ oscillation images and $15 \mathrm{~s}$ exposure each. The crystal was mounted in a random orientation at a crystal-to-detector distance of $100 \mathrm{~mm}$. As the crystal did not undergo detectable radiation damage, additional data were recorded to increase redundancy. The crystal belongs to the space group $\mathrm{P} 2{ }_{1} 2_{1} 2_{1}$ with unit cell dimensions

18 of $a=45.34 \AA, b=49.03 \AA$ and $c=54.91 \AA$. All diffraction data were reduced and scaled with HKL2000 package [23,24].

The diffraction data for the reduced crystal were collected on the undulator beam line ID14

21 EH4 at the European Synchrotron Radiation Facility. A $100^{\circ}$ data set was recorded at a 22 wavelength of $0.98 \AA$ with $1^{\mathrm{O}}$ oscillation steps. Data were processed as above [24]. Data 23 statistics are summarized in Table 1. 
1 Structure Determination and Refinement. The program CNS [25] was used to carry out

2 local scaling of the MAD data, perform automatic Patterson interpretations, locate the two

3 iron scatterers present in the asymmetric unit, refine heavy-atom parameters and perform

4 phase calculations. In the experimental map, most of the atomic model was built by the auto-

5 tracing option of the Warp program [26], whereas 11 residues (Pro33 to Asp36, Cys45 to

6 His49, Trp56 to Asp58, Asp69 to Ile71 and Ile106) mainly in loops were built manually with

7 the Baton-build option from the graphics program $\mathrm{O}$ [27]. Features of positive density greater

8 than $3 \sigma$ in the Fo-Fc difference Fourier maps were modeled as the 2 sulfur and 2 iron atoms

9 of the $[2 \mathrm{Fe}-2 \mathrm{~S}]$ cluster. The final crystallographic model was refined at $2.07 \AA$ resolution to

10 an $R$ factor of $19.6 \%$ and an $R_{\text {free }}$ of $21.1 \%$, with the data from the high energy remote

11 wavelength. There was one molecule per asymmetric unit, and the solvent content was

12 estimated to be about $50 \%$. All 106 residues of the ferredoxin sequence are included in this

13 final model, which consists of 797 protein atoms, $2 \mathrm{Fe}$ and 2 inorganic S atoms as well as 62

14 water molecules. The atomic coordinates have been deposited in the Protein Data Bank with

15 entry code 1E9M.

16

17

The structure of reduced FdVI was determined by molecular replacement with the AMoRE package[28], using as starting model the structure of the oxidized molecule, devoid of the cluster and the water molecules. The initial crystallographic R-factor was $39.7 \%$. The crystallographic model was refined to $2 \AA$ resolution using program CNS and program O as described above. Strong electron density was observed above the sulfur atoms of the cluster early in the refinement. Simulated annealing omit map suggested a non-planar conformation of the cluster. The cluster conformation was further refined according to the omit map by releasing all restrains on the cluster geometry. The positive and negative electron density found around residues 44 and 24 were interpreted as second conformations of these residues 
1 After a final annealing cycle with the CNS program, the $R$ and $R_{\text {free }}$ factors were $23.0 \%$ and $225.7 \%$, respectively. Ramachandran plot indicated that all residues were in the most favored 3 or additional allowed regions with the exception of Ala44. The coordinates have been 4 deposited in the Protein Data Bank as entry 1UWM. The refinement statistics of the models 5 for the oxidized and reduced proteins are summarized in Table 2.

6

Table 2 Structure comparisons of [2Fe-2S] containing proteins. The rms deviations between 8 structures were calculated using the MOE program (available at www.chemcomp.com). All 9 structure superpositions were done using the lsqkab program from the CCP4 suite [29]. 
3 Comparative genomics indicate that FdVI and its orthologs in $\alpha$ - and $\beta$-proteobacteria are involved in Fe-S cluster biosynthesis.

According to the current annotation of the $R$. capsulatus genome

6 (http://ergo.integratedgenomics.com/Genomes/R.capsulatus/proteins), there exist six

7 ferredoxin-encoding genes in this bacterium. All these ferredoxins have been previously

8 characterized, and it clearly appears that FdVI is the only one to show properties similar to

9 ferredoxins known to be involved in the assembly of iron-sulfur clusters [15]. As exemplified

10 by the E. coli $\mathrm{Fdx}$, these ferredoxins share a Cys- $\mathrm{X}_{3}-\mathrm{Cys}-\mathrm{X}_{1}-\mathrm{Cys}-\mathrm{X}_{2}-\mathrm{Cys}$ cluster binding 11 motif, where the second cysteine, which is not a ligand of the [2Fe-S] cluster, has been put forward as a possible ligand for an iron or a sulfur atom [11]. PSI-BLAST searches for bacterial homologues of FdVI in the data bases revealed a systematic occurrence of similar sequences in most Proteobacteria (purple bacteria and relatives). In some organisms such as Rhodopseudomonas palustris, paralogous [2Fe-2S] ferredoxins were found, sharing the Cys$\mathrm{X}_{5}$-Cys- $\mathrm{X}_{2}$-Cys motif common to vertebrate type-ferredoxins. Using the STRING webinterfaced software (http://www.bork.embl-heidelberg.de/STRING/) for predicting functional associations between gene products in whole genomes [30], we analysed, in the available genomes of proteobacteria, the occurrence and neighborhood associations between the eight genes of the iscSUA-hscBA-fdx-ORF3 operon found in E. coli and Azotobacter vinelandii.

21 The analysis showed that $f d x$ genes from most $\gamma$-Proteobacteria (Pseudomonas, Haemophilus, Escherichia) and $\beta$-Proteobacteria (Ralstonia, Chromobacterium) are clearly associated with iscSUA and/or $h s c B A$ genes involved in Fe-S cluster biosynthesis (Fig. S1 in 24 supplementary material). A few neighborhood associations are also observed in some $\alpha$ - 
1 scattered on the chromosome. Remarkably, most $\alpha$-Proteobacteria genomes show only one

2 isc-related $f d x$ gene, as well as single copies of the $i s c S U A$ and $h s c B A$ related genes. In

3 addition, a phylogenetic comparison of 37 vertebrate-type ferredoxin sequences showed a

4 striking correlation between the sequence relatedness and the taxonomical relationship

5 between microorganisms (data not shown). In this respect, FdVI appeared more closely

6 related to ferredoxins from other $\alpha$-Proteobacteria than to ferredoxins from $\beta$ and $\gamma$ -

$7 \quad$ Proteobacteria (Fig. 1). These findings, together with the sequence alignments with bona fide

8 isc-linked Fds (Fig.1), support the idea that FdVI and its orthologs in $\alpha$ - and $\beta$ -

9 Proteobacteria are involved in Fe-S cluster assembly, similar to their counterparts in

$10 \gamma$-Proteobacteria.

Fig. 1

\section{Circular dichroïsm and redox properties of FdVI}

In a previous study, we demonstrated that the recombinant ferredoxin considered herein was indistinguishable from the native $R$. capsulatus FdVI, based on UV-visible and EPR spectroscopy, as well as mass spectrometric measurements [17]. The protein was further characterized by circular dichroïsm spectroscopy. The spectrum of FdVI was very similar to those previously found for adrenodoxin, putidaredoxin, E. coli Fdx and A. vinelandii FdIV [31,32] (data not shown). It featured a shoulder at $450 \mathrm{~nm}$ and separate absorption bands in the $250-350 \mathrm{~nm}$ range which are typical of vertebrate-type Fds, and are not observed in the case of a representative plant-type ferredoxin [33]. This result further confirms that FdVI belongs to the former class of [2Fe-2S] ferredoxins.

Redox titrations of FdVI were first carried out at $23^{\circ} \mathrm{C}$ and at two different ionic strengths. The data were well fitted by a Nernst curve, yielding very similar midpoint potentials at $0.1 \mathrm{M}$ $\mathrm{NaCl}\left(\mathrm{E}^{\circ}=-306 \mathrm{mV} \pm 5 \mathrm{mV}\right)$ and at $1 \mathrm{M} \mathrm{NaCl}\left(\mathrm{E}^{\circ}=-296 \pm 5 \mathrm{mV}\right)$ (Fig. 2). The midpoint potential of FdVI was also found to be essentially temperature-independent in the 13 to $35^{\circ} \mathrm{C}$ 
1 range (Fig. 2b) resulting in an entropy variation $\Delta \mathrm{S}_{\mathrm{rc}}^{\circ}$ equal to $0 \pm 5 \mathrm{~J} \mathrm{~mol}^{-1} \mathrm{~K}^{-1}$. In contrast,

2 strong ionic strength dependence and a markedly negative $\Delta S_{\text {rc }}^{\prime}$ value were observed for $S$.

3 maxima ferredoxin (Fig.2b) and other plant-type ferredoxins [34]. A large entropy variation Fig. 2

$4 \Delta S_{\mathrm{rC}}^{\prime}=-207 \mathrm{~J} \mathrm{~mol}^{-1} \mathrm{~K}^{-1}$ has been previously reported for bovine adrenodoxin [35]. However,

5 recent non-isothermal potentiometric titrations of this protein performed at $0.1 \mathrm{M}$ and $1 \mathrm{M}$

$6 \mathrm{NaCl}$, yielded a much less negative value $\left(\Delta \mathrm{S}_{\mathrm{rc}}^{\prime \prime}=-20 \pm 10 \mathrm{~J} \mathrm{~mol}^{-1} \mathrm{~K}^{-1}\right.$; Bernardt, R., Asso, M.

7 and Bertrand, P., unpublished results). The very low entropy variation found for FdVI and

8 adrenodoxin compared to plant-type ferredoxins, may reflect differences in the solvent

9 accessibility of the cluster. This hypothesis is supported by comparisons of the molecular structures of relevant ferredoxins as will be discussed below.

\section{Overall fold of FdVI}

The structure of FdVI was determined from high quality MAD data sets (Table 1) obtained from oxidized crystals. The crystallographic model was refined at $2.07 \AA$ resolution to an $R$ factor of $19.6 \%$ and an $R_{\text {free }}$ of $21.1 \%$. As depicted in figure 3, the FdVI polypeptide displayed the typical $\alpha \quad \beta$ fold that was previously observed in other [2Fe-2S] Fds [2], featuring a twisted sheet that consists of the four major $\beta$-strands, and one major $\alpha$-helix adjacent to the sheet.

The polypeptide chain of FdVI is organized into a core domain which contains the cluster, and a large hairpin comprising residues between His49 and Leu84, which includes strand B3, and helices $\mathrm{H} 2$ and $\mathrm{H} 3$ (Fig. 3). The large hairpin, which is later referred to as interaction domain, was found to be more flexible than the core domain. Examination of the B factor distribution along the $\mathrm{C} \alpha$ main chain indicated that the interaction domain had a higher average value $\left(32 \AA^{2}\right.$ ) compared to the rest of the protein $\left(28.1 \AA^{2}\right)$ and to the overall structure $\left(29.2 \AA^{2}\right)$. 
1 Two extended hydrogen bond networks between the core and the interaction domains

2 significantly reduce the mobility of the latter. One of these networks is centered around His49

3 and involves Ser82 $\mathrm{O} \gamma$ - His $49 \mathrm{~N}_{2}$ and Arg83 O - Ala50 N which stabilize the B3 strand. The

4 second network is organized around His100 and includes the following H-bonds : Val98 O -

5 Asp53 N, His100 N - Tyr51 O, His100 O - Tyr51 N and His100 N $\varepsilon_{2}-$ Asp53 O $_{1}$. Residues

6 His49 and His100 form a hinge-like device linking the core and interaction domains, which

7 would make the molecule quite flexible, not taking into account the contribution of the

8 hydrogen bond networks. Furthermore, a hydrogen bond network bridged by water molecules

9 and involving residues 51 and 86 on the one hand, and residues 87 and 62, 64, 66, and 67 on

10 the other, further stabilizes the loop preceding helix $\mathrm{H} 3$.

\section{Comparison with related [2Fe-2S] ferredoxins}

13 Overall rms deviations of 1.0, 2.0 and $2.4 \AA$ were determined between the main chain $\mathrm{C} \alpha$ atoms of FdVI and those of Pdx, Adx and Fdx, respectively. The largest differences were observed between the interaction domains, C-termini and loop regions. From the sequence alignment shown in figure 1, there are fourteen amino acid residues that are strictly invariant, four of which are the ligand cysteines $39,45,48$ and 86 that link the [2Fe-2S] cluster to the protein (Fig. 3). The remaining invariant residues, Gly20, Thr47, His49, Glu67, Ile71, the Ser82 - Gln87 segment and Pro102 distinguish FdVI and homologous Fds from the plant-type Fds. Thr47 and His49 form with the ligand residue Cys48 a highly conserved pattern (ThrCys-His) among vertebrate-type ferredoxins. Thr47 $\mathrm{O} \gamma_{1}$ interacts through a $\mathrm{OH}-\mathrm{S} \gamma$ bond with the Cys45 cluster ligand which might be relevant to protein stability as suggested from studies on variants of Adx obtained by site-directed mutagenesis [36]. In addition, the hydroxyl group

24 of Thr47 is within H-bonding distance of the amide group of residues Ala37 and Asp38, a feature that is only observed in FdVI. 
1 Like in other vertebrate-type Fds, residue Glu67 has an important role in FdVI as it forms a

2 salt-bridge with Arg83. Disruption of this salt-bridge in human ferredoxin through site-

3 directed mutagenesis led to misfolding of the protein [37], suggesting that such a salt-bridge

4 is essential for the correct folding of the Fds [9]. Furthermore, Glu67 O is bonded to Met70 N

5 and Ile71 $\mathrm{N}$, the latter residue being in turn linked to Ala74 through a Ile71 O-Ala74 $\mathrm{N}$ bond.

6 The Ser82-Gln87 segment around the fourth ligand cysteine, is highly although not fully

7 conserved among vertebrate-type Fds [9](Fig. 1). The hydrogen bond between Gln87 and

8 Leu84 creates a hairpin loop that traps Cys86 in position. Also, the $\mathrm{H}$ bond between Gln87

$9 \quad \mathrm{~N} \varepsilon_{2}$ and Cys86 $\mathrm{S} \gamma$ is a feature shared by all vertebrate ferredoxins.

10 Pro102 is also conserved throughout this class of ferredoxins. Like Thr47 already mentioned

11 above, Pro102 plays a key role in maintaining the 3-D fold. It is involved in H-bonding 12 networks with neighbor residues Leu101 and Glu103. In the FdVI molecule, Pro102 is 13 connected through a water bridge to residues Glu7 and His8, thus providing a link between 14 the $\mathrm{C}$ and $\mathrm{N}$ termini. Furthermore, Pro102 is in contact with the aromatic polar residues His49, Tyr51 and Tyr75 providing additional links between the core and the interaction 16 domains.

17 A further analysis of the interactions that might be important for the 3D folding highlights the role of several water molecules. Such buried water molecules may not only help stabilizing the C-terminus and the interaction domain but also contribute to the redox properties of the [2Fe-2S] cluster via the H-bonding network that extends all the way from the cluster to the 21 surface of the molecule.

\section{The [2Fe-2S] cluster environment}

The $[2 \mathrm{Fe}-2 \mathrm{~S}]$ cluster is located at the edge of the molecule and shows a general configuration remarkably similar to that found in $\mathrm{Adx}, \mathrm{Pdx}$ and $\mathrm{Fdx}$, featuring a unique amide-to-sulfur 
1 NH-S bond Gln87 NE2 - Cys86 SG as well as the hydroxyl-to-sulfur OH-S bond between

2 Thr47 OG - Cys45 SG. The plant-type Fds do not contain these two interactions.

3 The cluster lies 5 to $6 \AA$ below the surface in a pocket delimited by residues forming the

4 cluster binding loop (Cys39 to Cys48), as well as by residues Met24, Met70 and Gln87. It is

5 buried in an hydrophobic environment in which none of the cysteine ligands is in contact with

6 the solvent. An internal channel lined by residues Gly40, Arg28, Glu25 and Asp29 would

7 give $\mathrm{S} 2$ access to the solvent, if the passage were not obstructed by the Met2 4 side chain. The

8 low accessibility of the cluster to the solvent, which was also observed in Adx, contrasts with

9 the situation found in plant-type ferredoxins, as previously reported by Müller et al.[2]

10 Indeed, in Anabaena Fd as well as in related Fds, a funnel leads from the surface of the

11 molecule to the vicinity of the cluster, resulting in the exposure of the Cys 49 cluster ligand to

12 the solvent. This difference in solvent accessibility established on the basis of structural

13 grounds might explain why the mid-point redox potential of plant-type ferredoxins is sensitive

to temperature and changes of the solvent ionic strength, whereas that of vertebrate-type Fds is much less sensitive to such changes.

FdVI features one non-ligand cysteine, Cys43, located in the cluster-binding loop preceding strand B3. An extra cysteine is present in the same position only in ferredoxins involved in the biogenesis of Fe-S clusters, such as E. coli Fdx, while it is missing in Adx and Pdx (Fig. 1). In FdVI, Cys43 makes bonds only with its neighbor residues Ala42 and Ala44. Examination of the Cys43 environment indicates that its side chain is in van der Waals 21 contact with the side chain of Glu67 and the S1 atom of the [2Fe-2S] cluster. Interestingly, the 22 side chain of Cys43 is oriented towards the protein surface so that its reactive thiol group is exposed to the solvent and surrounded by hydrophilic residues (Thr 66, Glu 67, Gln 87) (Fig. 4). A comparison of FdVI Cys43 with its counterpart in Fdx (Cys46) shows that they are Fig. 4

25 located on the same side of the cluster, and that their thiol group is similarly pointed towards 
1 the solvent. In E. coli Fdx, Cys46 has been proposed to provide, through its thiol group, a

2 potential ligand for a sulfur atom or $\mathrm{Fe}^{3+}$ ion, during the process of $\mathrm{Fe}-\mathrm{S}$ cluster assembly

$3[11]$

4

\section{$5 \quad$ Charge distribution and Interaction domain}

6 Overall, the electrostatic potential of the surface of FdVI is almost neutral (Fig.5) which Fig. 5

7 results into a remarkably small dipole moment compared to most ferredoxins. The 8 asymmetric distribution of charges at the surface of [2Fe-2S] ferredoxins, with more negative

9 charges near the active site, is generally thought to favor the correct orientation of Fds while 10 docking with their redox partner. Four acidic residues of Adx (Asp79, Asp76, Glu73 and 11 Asp72) were shown to be involved in the interaction with cytochrome P450[37]. Two of these residues, Asp76 and Asp79, are also required for the recognition of the reductase. In FdVI, 13 only two of these negatively charged residues are conserved (Asp69/Asp72 in place of Asp76/Asp79 in Adx), whereas Pro65 and Thr66 replace Asp72 and Glu73 in Adx. A pair of aspartate residues in position equivalent to Asp69 and Asp72 in FdVI is also encountered in most ferredoxin sequences (Fig. 1), including Fds thought to participate in iron-sulfur cluster biosynthesis in $\gamma$-Proteobacteria and yeast. A representative of this subclass of Fds, E. coli Fdx, displays on its surface, numerous acidic residues which form two markedly negative patches on one side of the molecule[11]. In FdVI, most of the corresponding residues are replaced by hydrophobic or basic residues (Fig. 1). In this respect, FdVI is similar to Pdx which also showed an atypical distribution of charges resulting in a neutral surface charge[12]. Pdx lacks the pair of Asp residues supposedly involved in the interaction with the reductase in other Fds. Instead, it was found that Glu72 and Cys73 were important for the interaction of Pdx with its cognate reductase, whereas Asp38 and Trp106 are required for 
1 binding to the cytochrome P450cam[38]. Kinetics studies showed that the association of Pdx

2 with the reductase was driven by non-electrostatic interactions [39].

\section{Structural changes induced upon reduction}

5 EPR and spectrophotometric measurements showed that FdVI was readily and fully reduced

6 by $2 \mathrm{mM}$ dithionite when in solution in the crystallization buffer at a protein concentration around $0.5 \mathrm{mM}$ (Fig. S2 in supplementary material). However, the reduced protein failed to crystallize when incubated under conditions similar to those promoting the crystallization of the oxidized form. As another option, oxidized crystals were soaked in a defined reducing solution and the extent of FdVI reduction was checked by micro-spectrophotometry. As illustrated in Fig. 6, the spectrum of the reduced crystal exhibited a lower absorption in the range $380-650 \mathrm{~nm}$ and a prominent absorption band around $544 \mathrm{~nm}$, similar to the reduced protein in solution (Fig. S2). The $\mathrm{A}_{414} / \mathrm{A}_{544}$ ratio, taken as an indicator of the extent of reduction, was calculated to be 2.80 and 1.30 for the oxidized and the reduced crystal, respectively. The corresponding values for the protein in solution were 2.65 for the oxidized, and 1.60 for the fully reduced protein. While these data suggested that the ferredoxin in the crystal underwent extensive reduction, accurate determination of the extent of reduction was precluded by the fact that the spectrum of the reduced crystal exhibited distinct features compared to that of the protein in solution, including the occurrence of an additional absorption band near $440 \mathrm{~nm}$.

The structure of the reduced crystal was solved at $2.0 \AA$ resolution. The fold of FdVI in the reduced crystal was found to be almost identical to that of the oxidized molecule, with an overall rms deviation of $0.9 \AA$ As As shown in Fig. 4, largest differences between the reduced and oxidized molecules are observed in the interaction domain and in the vicinity of the cluster. Analysis of the density maps of the reduced crystal strongly suggested that the cluster 
1 underwent distortion. Density greater than $3 \sigma$ in the difference Fourier maps was detected

2 near the cluster after one cycle of refinement, indicating that the cluster geometry changed

3 from a planar to a distorted lozenge (Fig.7). Calculation of an omit map at this stage of the

4 refinement confirmed the distortion of the cluster (Fig. S3). In the fully refined model,

5 positive density was also observed above the S2 atom of the cluster, suggesting some

6 dynamical disorder or an alternate conformation of the cluster. Based on the electron density

7 maps, the S2 atom would occupy two positions $0.5 \AA$ apart, which could result from a

8 translation of this atom in a plane perpendicular to the cluster plane. In figure $7 \mathrm{~b}$ and $7 \mathrm{c}$, the

9 S2 atom is shown in an average position which corresponds to a minimum of density in the

10 difference Fourier map. Positive density was also detected in the vicinity of the S1 atom,

11 suggesting a possible movement of this atom which could not be accurately determined at 2

$12 \AA$ of resolution. Despite this conformational change, the Fe-S distances within the cluster

13 underwent no significant variation (Table 3).

Table 3

14 Examination of difference Fo-Fc maps also indicated the presence of alternate conformations

15

for two residues, Met24 and Ala44. One of the two conformations was virtually identical to that found in the oxidized crystal. In the other conformation, the side chain of Met24 underwent a $180^{\circ}$ rotation, approaching the $\mathrm{S} 2$ atom of the cluster at $2.84 \AA$ (Fig. $7 \mathrm{~b}$ ). At the same time, the H-bond between Met24 O and Arg28 N which was observed in the oxidized molecule was broken. This second conformation of Met 24 accounted for about $40 \%$ of the molecules in the crystal.

In the oxidized ferredoxin, the Ala44-CO pointed away from the cluster ("CO out"), whereas In the reduced crystal, Ala44 showed an additional conformation where the carbonyl came closer to the cluster S1 atom, at a distance of $3.9 \AA$ ("CO in"). The "CO out" and "CO in" conformations had calculated occupation rates of about $60 \%$ and $40 \%$, respectively, in the reduced crystal. In the "CO in" conformation, the Ala44 carbonyl turned toward Met70, thus 
1 reducing the distance from Ala44-O to Met70-S from 4.7 to $3.0 \AA$. This conformational flip of

2 the Ala44 carbonyl group was associated with higher B-factors for neighboring residues. The

3 alternate conformations of Met24 and Ala44 observed in the reduced crystal likely represent

4 the main structural changes occurring in the vicinity of the cluster upon reduction.

5 When compared to oxidized FdVI, the reduced ferredoxin was characterized by a higher level 6 of H-bonding, especially at the interface between the core and the interaction domains.

7 Moreover, the reduced crystal showed a higher content of water molecules (Table 2), many of 8 which were involved in bridges linking distant residues. For example, in the reduced 9 ferredoxin, the C-terminal Leu101 residue is linked to the $\mathrm{N}$-terminal His8 through two water molecules. An extension of the hydrogen bonding network was also noticed around residues 11 Arg28 and His49. In the reduced ferredoxin, four water molecules were involved in links between Arg28 and residues Thr22, Glu25, Ala37 and Gly40, thereby stabilizing the helix H1 and the loop preceding $\beta$-sheet B3. In the vicinity of His49, two new bonds linked Tyr75 O and Tyr75 N to His49 N81 through a water molecule, and another water molecule connected Gln105 to His49 and Tyr75. Taken together, the changes observed in the FdVI crystal upon reduction all contributed to decrease the flexibility of the protein and to tighten the molecular interaction between the core domain, the interaction domain and the C-terminus. This is reflected by a lower average B factor found for the reduced crystal compared to the oxidized crystal. Similar differences in B factors were observed when comparing the data collected on three oxidized crystals with those obtained for another reduced crystal.

\section{Comparison of redox-linked structural changes in FdVI, Pdx, Adx and AnFd}

So far, high resolution crystal structures of reduced [2Fe-2S] ferredoxins have been described in only two cases, the plant-type Anabaena PCC7119 Fd (AnFd) [40] and Pdx [41]. As for FdVI, the redox-mediated changes were deduced from a comparison of the X-ray structures of 
1 the relevant proteins obtained from oxidized and reduced crystals. In the plant-type AnFd,

2 reduction gave rise to relatively limited conformational changes around residues Cys46, Ser47

3 and Phe65 [40]. In the two vertebrate Fds considered herein, structural changes included a

4 movement of the cluster, conformational shifts of residues in the vicinity of the cluster, and an

5 extension of the H-bonding network linking the core and the interaction domains. The FdVI

6 cluster switched from a planar to a distorted lozenge geometry, a conformational change that

7 has not been observed in the Fds described so far. As the significance of this change is still

8 unclear, it is worth noting that some [2Fe-2S] Fds, including $\mathrm{AnFd}$, have been shown to

9 harbor a non-planar cluster[40]. In FdVI, two redox-induced conformational shifts occurred

10 in the vicinity of the cluster, involving residues Ala44 and Met24. The movement of the

11 Met24 side chain resulted in the S $\delta$ atom approaching the S2 atom of the cluster at less than

$122.9 \AA$. The proximity of this electron rich sulfur atom might stabilize the reduced state of the

13 cluster or tune its redox potential by changing the electrostatic environment. The potential

14 role of the Met24 residue in controlling the redox potential of FdVI can be investigated by

15 amino acid substitution through site-directed mutagenesis.

16 The flip of the Ala44 carbonyl which points towards the cluster in the reduced state (COin), is reminiscent of a similar carbonyl flip previously observed in $\mathrm{Pdx}$ and AnFd, with two important differences : in the latter cases, the CO flip concerns the cysteine residue adjacent to Ala44, and the $\mathrm{CO}$ orientation is opposite, pointing outwards in the reduced state. In AnFd, the Cys46-Ser47 link lies in close contact with the Phe65 aromatic ring which plays a crucial 21 role in electron transfer to the cognate reductase FNR. From this observation, it has been proposed that the carbonyl flip might trigger the dissociation of the AnFd-FNR complex after electron transfer [42] . In reduced Pdx, the conformational shift of the Cys45 carbonyl allows formation of a $\mathrm{H}$ bond between $\mathrm{Ala} 46 \mathrm{~N}$ and the $\mathrm{S} 1$ atom of the cluster, and initiates a 
1 reduced FdVI, the corresponding carbonyl stayed in the COin orientation while the carbonyl

2 of the preceding peptide bond turned to face Met70. Interestingly, Met70 occupies a position

3 similar to Phe65 in AnFd, and given that Phe65 plays a critical role in the electron transfer to

4 FNR, it is inferred that the CO switch of Ala44 might be involved in the interaction of FdVI

5 with its natural partner.

6 FdVI reduction was also accompanied by an extension of the $\mathrm{H}$ bond network which further rigidified the structure of the molecule and prevented movement between the core and the interaction domains. A similar increase of the intramolecular $\mathrm{H}$ bonding was observed in $\mathrm{Pdx}$ upon reduction, which not only stabilized the peptide binding loop around the cluster but also modified the surface area supposed to interact with cytP450 [41] . In Adx, an NMR study

11 showed that reduction induced conformational changes in the C-terminal region of the molecule, causing the dissociation of the dimeric oxidized form[43] . In another study, it was found that oxidized Adx was more dynamic than the reduced protein, and that His56, which lies at the interface between the core and the interaction domains, was required for the redox dependent changes observed upon reduction[44] . Likewise, the His49 residue of FdVI which occupies a position similar to His56 in Adx, was found to play a pivotal role in linking the core and the interaction domains and in stabilizing the reduced protein.

Despite obvious structural similarities between FdVI, Pdx and Adx, and to a lesser extent AnFd, the work described here and in previous studies[40,41,43] indicates that the three proteins exhibited clearly distinct behaviour upon reduction. The observed differences likely reflect functional adaptation between each ferredoxin and its cognate protein partners. 
1 We thank Christine Meyer for helping in the purification of FdVI. We are indebted to Emile

2 Duée and Eric Fanchon for helpful discussion. Thanks to D. Bourgeois, X. Vernede, R.

3 Morales and J. Fontecilla for helpful advices and for giving us access to the facilities which

4 allowed to obtain and analyze reduced crystals of FdVI. We wish to thank Valerie Biou, Janet

5 Smith and Andrew Thompson, for valuable suggestions and support. Funding for this project

6 was provided by the Centre National de la Recherche Scientifique, the Commissariat à

7 l'Energie Atomique, the European Synchrotron Radiation Facility, and the NIGMS under 8 agreement Y1 GM-0080.

9 
3 [1] Bruschi, M. and Guerlesquin, F. (1988) FEMS Microbiol. Rev. 54, 155-176.

4 [2] Muller, J.J., Muller, A., Rottmann, M., Bernhardt, R. and Heinemann, U. (1999) J.

\section{References}

Mol. Biol. 294, 501-513.

[3] Bernhardt, R. (1996) Rev Physiol Biochem Pharmacol 127, 137-221.

[4] Baldwin, J.E., Morris, G.M. and Richards, W.G. (1991) Proc R Soc Lond B Biol Sci 245, 43-51.

[5] Berg, A., Gustafsson, J.A. and Ingelman-Sundberg, M. (1976) J Biol Chem 251, 28312838.

[6] Zheng, L., Cash, V.L., Flint, D.H. and Dean, D.R. (1998) J Biol Chem 273, 1326413272.

[7] Takahashi, Y. and Nakamura, M. (1999) J. Biochem. (Tokyo) 126, 917-926.

[8] Lange, H., Kaut, A., Kispal, G. and Lill, R. (2000) Proc. Natl. Acad. Sci. U.S.A. 97, 1050-1055.

[9] Grinberg, A.V., Hannemann, F., Schiffler, B., Muller, J., Heinemann, U. and Bernhardt, R. (2000) Proteins:Struct. Funct. Genet. 40, 590-612.

[10] Muller, A., Muller, J.J., Muller, Y.A., Uhlmann, H., Bernhardt, R. and Heinemann, U. (1998) Structure 6, 269-280.

[11] Kakuta, Y., Horio, T., Takahashi, Y. and Fukuyama, K. (2001) Biochemistry 40, 11007-11012.

[12] Sevrioukova, I.F., Garcia, C., Li, H.Y., Bhaskar, B. and Poulos, T.L. (2003) J. Mol. Biol. 333, 377-392.

[13] Armengaud, J., Meyer, C. and Jouanneau, Y. (1994) Biochem. J. 300, 413-418. 
1 [14] Grabau, C., Schatt, E., Jouanneau, Y. and Vignais, P.M. (1991) J. Biol. Chem. 266, 3294-3299.

[15] Naud, I., Vinçon, M., Garin, J., Gaillard, J., Forest, E. and Jouanneau, Y. (1994) Eur. J. Biochem. 222, 933-939.

[16] Armengaud, J., Meyer, C. and Jouanneau, Y. (1997) J. Bacteriol. 179, 3304-3309.

[17] Armengaud, J., Sainz, G., Jouanneau, Y. and Sieker, L.C. (2001) Acta Crystallogr. D 57, 301-303.

[18] Bourgeois, D., Vernede, X., Adam, V., Fioravanti, E. and Ursby, T. (2002) J. Appl. Cryst. 35, 319-326.

[19] Bertrand, P. and Gayda, J.P. (1979) Biochim. Biophys. Acta 579, 107-121.

[20] Tanigushi, V.T., Sailasuta-Scott, N., Anson, F.C. and Gray, H.B. (1980) Pure Appl. Chem. 52, 2275-2281.

[21] Evans, G. and Pettifer, R.F. (2001) J. Appl. Cryst. 34, 82-86.

[22] Westbrook, E.M. and Naday, I. (1997) Methods Enzymol. 276, 244-268.

[23] Otwinowski, Z. (1993) in: Data Collection and Processing, Proceedings of the CCP4, pp. 56-62 (Bailey, S., Ed.) SERC Laboratory, Daresbury, Warrington, UK.

[24] Otwinowski, Z. and Minor, W. (1997) Methods Enzymol. 276, 307-326.

[25] Brünger, A.T. et al. (1998) Acta Crystallogr. D54, 905-921.

[26] Perrakis, A., Morris, R. and Lamzin, V.S. (1999) Nat Struct Biol 6, 458-463.

[27] Jones, T.A., Zou, J.-Y., Cowan, S.W. and Kjeldgaard, M. (1991) Acta Crystallogr A47, 110-119.

[28] Navaza, J. (1994) Acta Crystallogr A50, 157-163.

[29] CCP4 (1994) Acta Crystallogr. D50, 760-763.

[30] von Mering, C., Huynen, M., Jaeggi, D., Schmidt, S., Bork, P. and Snel, B. (2003) Nucleic Acids Research 31, 258-261. 
1 [31] Ta, D.T. and Vickery, L.E. (1992) J. Biol. Chem. 267, 11120-11125.

2 [32] Jung, Y.S., Gao-Sheridan, H.S., Christiansen, J., Dean, D.R. and Burgess, B.K. (1999) J. Biol. Chem. 274, 32402-32410.

[33] Hase, T., Mizutani, S. and Mukohata, Y. (1991) Plant Physiol. 97, 1395-1401.

[34] Battistuzzi, G., D'Onofrio, M., Borsari, M., Sola, M., Macedo, A.L., Moura, J.J. and Rodrigues, P. (2000) J Biol Inorg Chem 5, 748-760.

[35] Huang, Y.Y. and Kimura, T. (1983) Anal. Biochem 133, 385-393.

[36] Burova, T.V., Beckert, V., Uhlmann, H., Ristau, O., Bernhardt, R. and Pfeil, W.

[37] Coghlan, V.M. and Vickery, L.E. (1991) J Biol Chem 266, 18606-12.

[38] Holden, M., Mayhew, M., Bunk, D., Roitberg, A. and Vilker, V. (1997) J. Biol. Chem. $272,21720-21725$.

[39] Sevrioukova, I.F., Hazzard, J.T., Tollin, G. and Poulos, T.L. (2001) Biochemistry 40,

[44] Kostic, M., Bernhardt, R. and Pochapsky, T.C. (2003) Biochemistry 42, 8171-82.

[45] Esnouf, R.M. (1997) J. Mol. Graphics 15, 133-138. 
1 [47] Nicholls, A., Sharp, K.A. and Honig, B. (1991) Proteins: Struct.Funct.Genet. 11, 2812 296.

3

4 
1 Table 1: Crystallographic data used for the phasing (oxidized crystal) and for the

2 molecular replacement (reduced crystal). Calculations were carried out with the CNS

3 program.

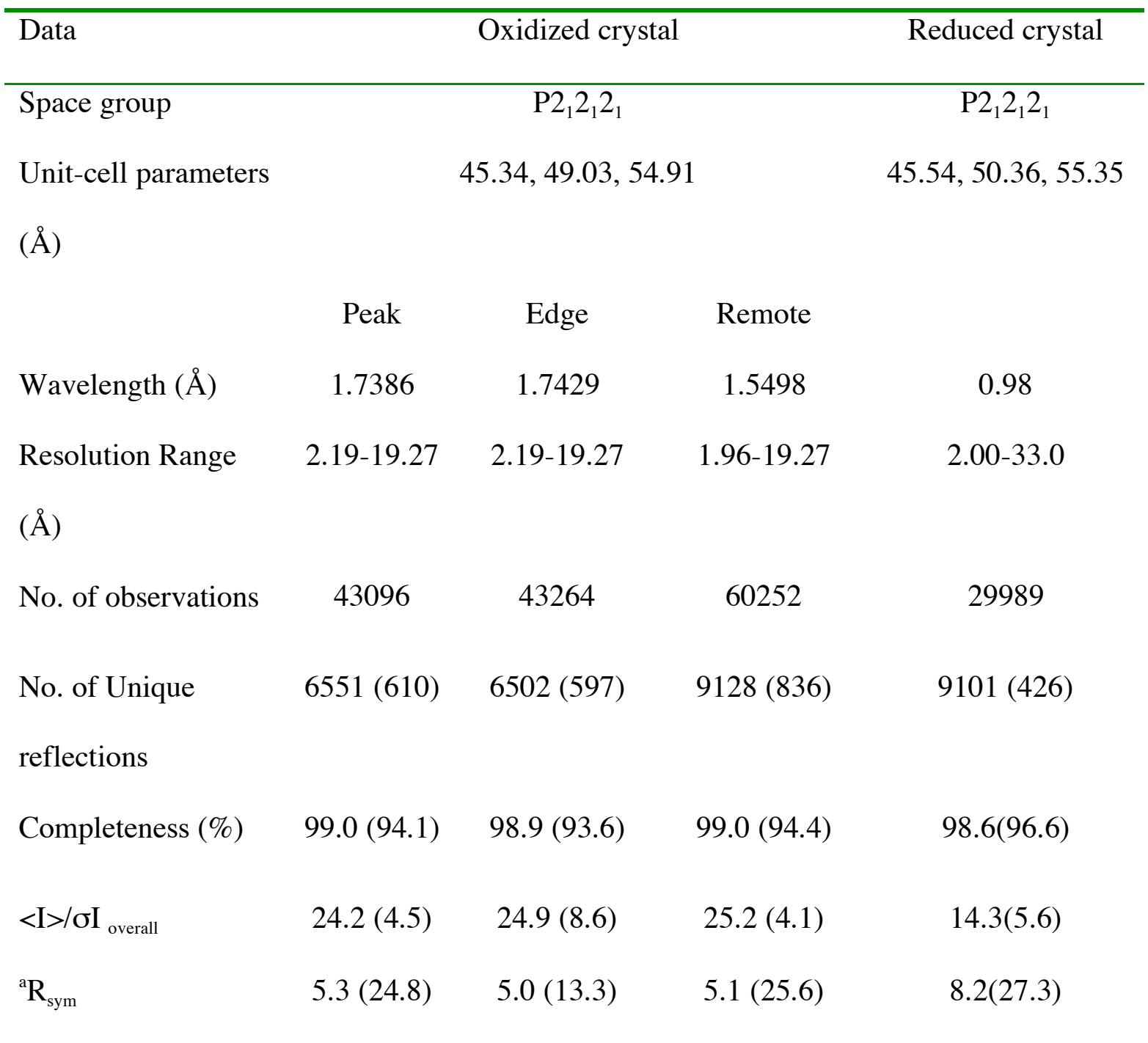

4

$5 \quad{ }^{a} R_{\text {sym }}=\sum\left|\mathrm{I}_{\mathrm{i}^{-}}<\mathrm{I}>\mathrm{I} / \sum<\mathrm{I}_{\mathrm{i}}\right\rangle$, where $\mathrm{I}_{\mathrm{i}}$ is the intensity of the ith observation and $\left\langle\mathrm{I}_{\mathrm{i}}\right\rangle$, is the mean

6 intensity of the reflection.

7 Numbers in parentheses gave statistics in the highest resolution range :

$8 \quad 2.28 \AA-2.20 \AA$ for the peak and inflection data from the oxidized crystal

$92.03 \AA-1.96 \AA$ for the reduced crystal

10

12 Table 2: Summary of the refined FdVI model statistics. 


\begin{tabular}{lcc}
\hline Model Refinement & Oxidized crystal & Reduced crystal \\
\hline Resolution range $(\AA)$ & $19.27-2.07$ & $28.83-2.00$ \\
Data cutoff & $|\mathrm{F}|>0$ & $|\mathrm{~F}|>0$ \\
$\mathrm{R}_{\text {work }}(\%)^{\mathrm{a}}$ & 19.6 & 23 \\
No. of reflections & 7256 & 8911 \\
$\mathrm{R}_{\text {free }}(\%)^{\mathrm{b}}$ & 21.1 & 25.7 \\
No. of reflections & 397 & 912 \\
overall anisotropic scale factors & & -4.18 \\
$\mathrm{~B}_{11}$ & -7.719 & -6.29 \\
$\mathrm{~B}_{22}$ & -5.124 & 10.47 \\
$\mathrm{~B}_{33}$ & 12.843 &
\end{tabular}

Refined model

residues

1-106 1-106

No. of protein atoms

797

797

No. of cluster atoms

4

4

No. of solvent atoms

62

142

Average B-factor $\left(\AA^{2}\right)$

Protein

32.2

15.2

Cluster

24.8

10.1

Solvent

59.1

28.3

All atoms

32.8

17

Rms deviations from target values

Bond length $(\AA)$

0.005

0.014

Bond angles (deg.)

1.3

1.7 
Estimated coordinate error $(\AA)$

$\begin{array}{lll}\text { Luzzati } & 0.27 & 0.31\end{array}$

$\begin{array}{lll}\text { SigmaA } & 0.20 & 0.27\end{array}$

$1 \quad{ }^{a} \overline{R_{\text {work }}}=\sum|| F_{o}|-| F_{c}|| / \sum\left|F_{o}\right|$

$2 \quad{ }^{\mathrm{b}} \mathrm{A}$ random $5 \%$ and $10 \%$ subset of the data was used for the $\mathrm{R}_{\text {free }}$ calculation, in the case of

3 the oxidized and the reduced crystal, respectively.

4 
1 Table 3 : Geometry of the FdVI [2Fe-2S] cluster in the oxidized and reduced crystals.

2 Interatomic distances in the $[2 \mathrm{Fe}-2 \mathrm{~S}]$ cluster are given in $\AA$. Angles are in degrees.

\begin{tabular}{lcc}
\hline Parameter & Oxidized & Reduced \\
\hline Distances & 3.6 & 3.6 \\
S1 S2 & 2.8 & 2.8 \\
Fe1 Fe2 & 2.2 & 2.3 \\
S1 Fe1 & 2.3 & 2.2 \\
S1 Fe2 & 2.3 & 2.3 \\
S2 Fe2 & 2.3 & 2.4 \\
S2 Fe1 & 2.3 & 2.2 \\
Fe1 S39 & 2.3 & 2.3 \\
Fe1 S45 & 105.1 & 105.9 \\
Fe2 S86 & 2.4 & 2.3 \\
Fe2 S48 & 2.2 & 2.3 \\
Angles & & \\
Fe1 S1 Fe2 & & \\
Fe1 S2 Fe2 & & \\
S1 Fe2 S2 & & \\
\hline
\end{tabular}

3

4 


\section{$1 \quad$ Figure legends}

2 Figure 1 : Sequence alignment of representative vertebrate-type [2Fe-2S] ferredoxins. The

3 alignment was performed using VectorNTI software. The numbering refers to the FdVI

4 sequence. Secondary structures are shown as arrows ( $\beta$-strands) and boxes ( $\alpha$-helices) above

5 the sequence. Highly conserved residues are shown in bold letters and invariant residues are

6 shaded. The vertical arrow points at a non-ligand cysteine conserved in isc-linked Fds. The

7 abbreviations used are : RHOCA for $R$. capsulatus B10 FdVI (Fer6_RHOCA), CAUCR for

8 Caulobacter crescentus CB15 Fd2 (CC3524), SINME for Sinorhizobium meliloti Fd

9 (SMCO0192), RICPR for Rickettsia prowazekii Fd (RP199), BRUME for Brucella melitensis

10 16M Fd (BMEI0959), RALSO for Ralstonia solanacearum GMI1000 Fd (RSC1025), NEIME

11 for Neisseria meningitidis MC58 Fd (NMA1344), PSEAE for Pseudomonas aeruginosa

12 PA01 Fd (PA3809), HAEIN for Haemophilus influenzae Fd (HI0372), ECOLI for

Escherichia coli K12 Fd (B2525), AZOVI for Azotobacter vinelandii Fd (T44286), SACCE

for Saccharomyces cerevisiae Yah1p (YPL252c) (residues 59-172), ADRED for bovine adrenodoxin (BAA00362) (residues 4-108), and PUTID for putidaredoxin from Pseudomonas putida (P00259).

Figure 2 : Redox properties of FdVI.

a: Reductive titration of FdVI with dithionite. The FdVI concentration was $42 \mu \mathrm{M}$ in $1.0 \mathrm{M}$ $\mathrm{NaCl}$, Tris-HCl buffer, $\mathrm{pH}$ 8.0. Stepwise dithionite reduction of the ferredoxin was monitored by optical absorbance measurements at $456 \mathrm{~nm}$, at $23{ }^{\circ} \mathrm{C}$. The normalized variations correspond to the ratio $\left(\mathrm{A}_{\mathrm{E}}-\mathrm{A}_{\mathrm{red}}\right) /\left(\mathrm{A}_{\mathrm{ox}}-\mathrm{A}_{\mathrm{red}}\right)$. The solid line shows the best fit with a Nernst curve centered at $-296 \mathrm{mV}$.

24 b: Temperature dependence of the midpoint potential of FdVI. The temperature dependence of the midpoint potential $\mathrm{E}^{\circ}$ of $\mathrm{FdVI}$ from $R$. capsulatus for two $\mathrm{NaCl}$ concentrations $(\square=$ 
$11 \mathrm{M}, \boldsymbol{\square}=0.1 \mathrm{M})$ was compared with that of $S$. maxima ferredoxin $(\bigcirc=1 \mathrm{M}, \bullet=0.1 \mathrm{M})$.

2 The solid lines correspond to $\Delta \mathrm{S}_{\mathrm{rc}}^{\circ}$ values equal to 0 and $-52 \mathrm{~J} \cdot \mathrm{mol}^{-1} \cdot \mathrm{K}^{-1}$ for FdVI and $S$.

3 maxima ferredoxins, respectively.

4

5 Figure 3: Ribbon representation of the FdVI protein structure in the oxidized (a) and reduced

6 (b) states. The core and interaction domains are drawn in green and red, respectively. The $7 \quad[2 \mathrm{Fe}-2 \mathrm{~S}]$ cluster is represented in a stick-and-ball mode ( $\mathrm{Fe}$ and $\mathrm{S}$ atoms are shown in purple 8 and yellow, respectively). The side chains of residues Met24, Met70, Cys43, His49 and

9 His100 are shown. In the case of the reduced crystal, only the conformation which is thought to correspond to the fully reduced molecule is displayed. The figure was drawn using BOBSCRIPT [45].

Figure 4 : Closeup view of the polypeptide region surrounding Cys43 in FdVI. The drawing shows the $[2 \mathrm{Fe}-2 \mathrm{~S}\}$ cluster, the polypeptide backbone of the core (green) and the interaction (red) domains, and the side chains of residues in close proximity to Cys43. Distances between Cys43 S and nearest atoms are indicated as broken lines: Cys43 S-Gln87 N , 4.1

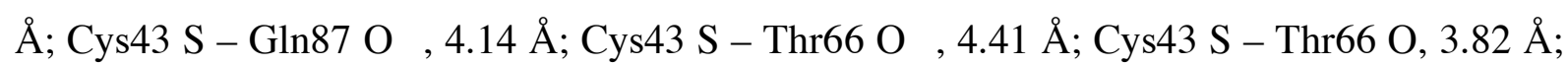
Cys43 S - Glu67 O 1, $6.16 \AA$ ^; Cys43 S - Glu67 O 2, $6.91 \AA ̊$. The figure was drawn with a modified version of MOLSCRIPT [45] and rendered with Raster 3D [46]

21 Figure 5 : Distribution of electrostatic potentials on the surface of oxidized FdVI. Basic and acidic residues are shown in blue and red, respectively. The views shown in (a) and (b) were obtained by rotating the molecule by 180 degrees around a vertical axis. The figure was drawn using GRASP [47] 
$1 \quad$ Figure 6 : Optical absorption spectra of FdVI crystals .

2 Spectra were recorded at $100 \mathrm{~K}$ on either an oxidized crystal (broken line) or a crystal reduced

3 with dithionite (continuous line). The same reduced crystal was used for X-ray structural

4 determination. The two spectra are presented with a vertical offset for the sake of clarity.

5 Relevant absorption maxima are indicated.

6

7 Figure 7 : Close-up view of the $[2 \mathrm{Fe}-2 \mathrm{~S}]$ environment in the oxidized and reduced crystals.

8 The drawings show the cluster, the four cysteine ligands and the Met24 side chain with the

$92 \mathrm{Fo}-\mathrm{Fc}$ and $\mathrm{Fo}-\mathrm{Fc}$ densities contoured at $1 \sigma$ (grey), $+3 \sigma$ (blue) and $-3 \sigma$ (red). The

10 conformation observed in the oxidized crystal (a) is compared to the average conformation

11 observed in the reduced crystal (b). Panel $\mathrm{c}$ is another view of the reduced cluster in a

12 different orientation, showing positive difference electron density in the vicinity of the S2

13 atom. The distance between Met24 S $\delta$ and S2 is indicated.

14 


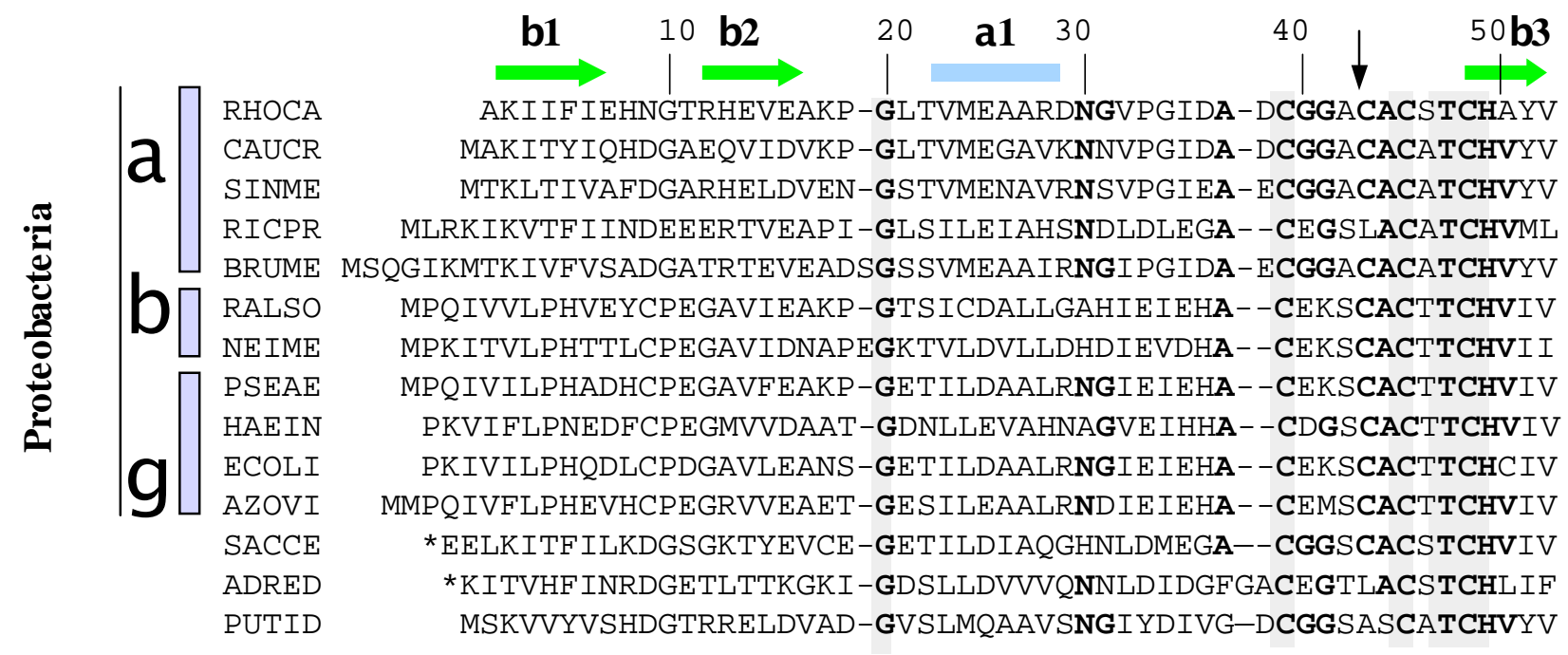

$80 \quad$ b4 a4 $90 \quad$ a5 $\quad 100$ b5

\section{a2 60}

|

$\stackrel{a}{\longrightarrow}$

DPAWVDKLPKALP TE TDMIDFAYEPNPATSRLTCQIKVTSLLDGLVVHLPEKQI

DEAWLDKTGDKSAMEESMLDF AENVEP-NSRLSCQIKVSDALDGLVVRLPESQH

DDAWAAQVGTPEAMEEDMLDF AYDVRP-TSRLSCQIKMSEALDGLVVHVPERQA

EEEFYNKLKKP TEAE EDMLDLAF GLTD-TSRLGCQI I LTEELDG IKVRLP SATRNIKI

DDDWADTVGGPDPMEEDMLDFAYEVRP-TSRLSCQIRVTDDLEGLVVQVPERQN

-REGFDSLGEATEKEEDLIDKAWGLEP-NSRLSCQAKVADE--DLTVE IPKYS INHAKETH

-RKGFDSLEEP TELEEDLLDQAWGLEA-DSRLSCQAVVAGE--DLIVE IPKYTINHAREEH

-REGLDSMEP SDELEDDMLDKAWGLEP-DSRLSCQAVVADE--DLVVE IPKYT INQVSEGH

-REGFDSLNET SDQEEDMLDKAWGLEM-DSRLSCQCVVGNE--DLVVE IPKYNLNHANEAAH

-REGFD SLP ESSEQEDDMLDKAWGLEP-ESRLSCQARVTDE--DLVVE IPRYTINHAREH

-RD GF DSLEP SDELEDDMLDKAWGLEP-ESRLSCQARVGTE--DLVVE IPRYT INQVSEQH

DPDYYDALPEPEDDENDMLDLAYGLTE-TSRLGCQIKMSKDIDGIRVALPQMTRNNNDFS

EQH IFEKLEA ITDEENDMLDLAYGLTD-RSRLGCQICLTKAMDNMTVRVP

NEAFTDKVPAANERE I GMLECVTAELKPNSRLCCQI IMTPELDG IVVDVPDRQW

Figure 1 


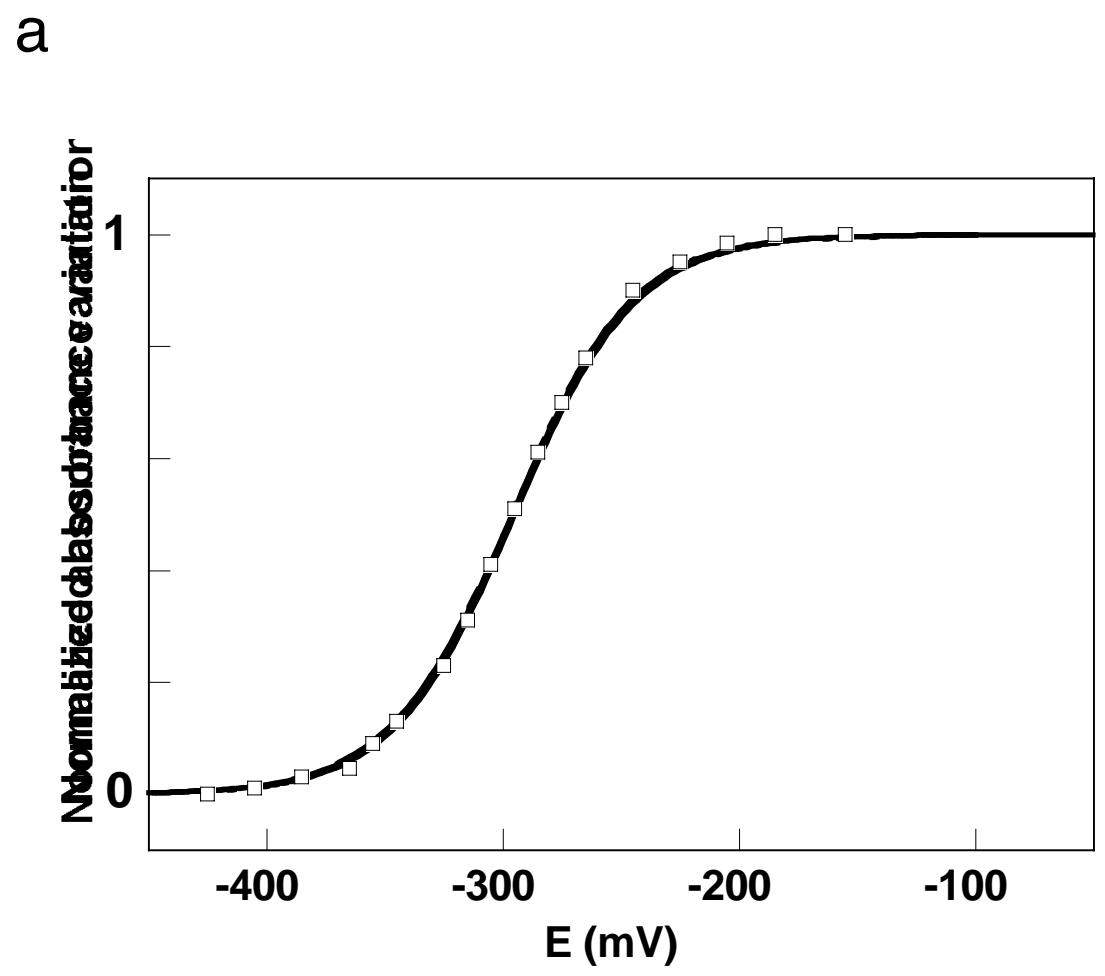

b

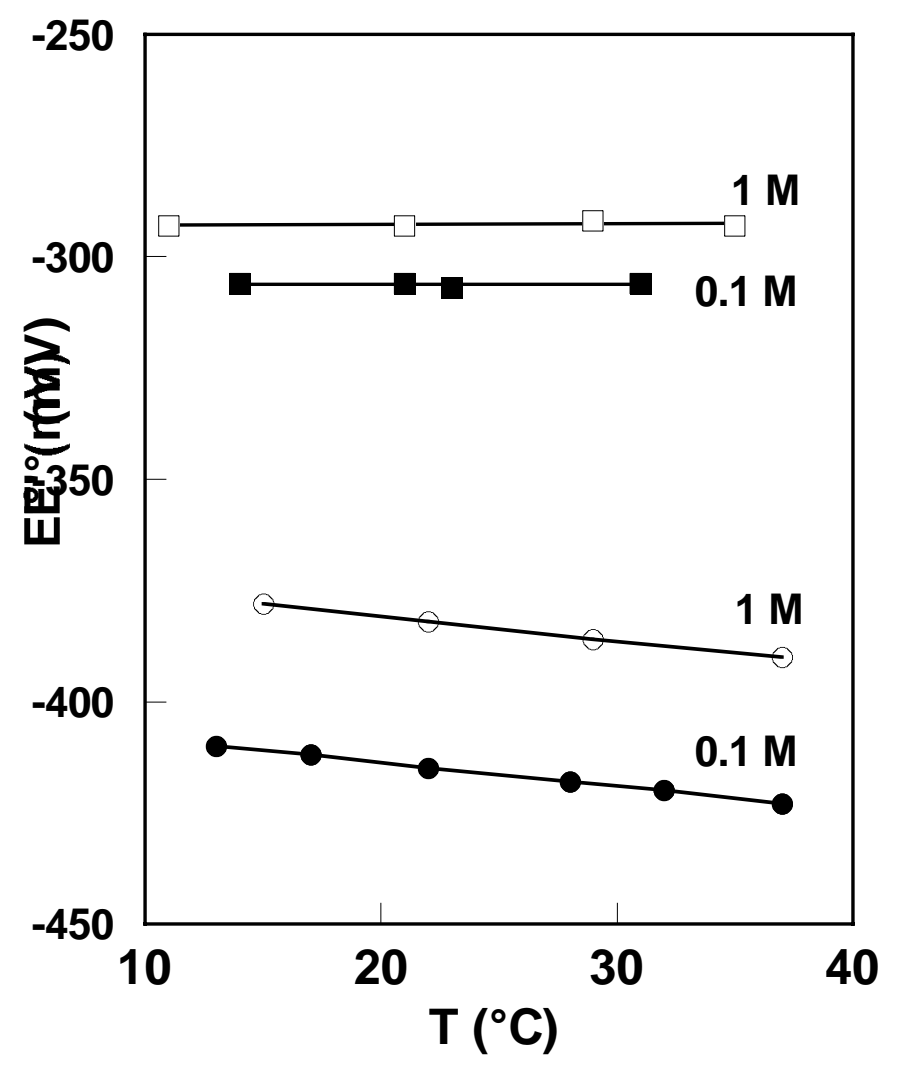

Figure 2 
a

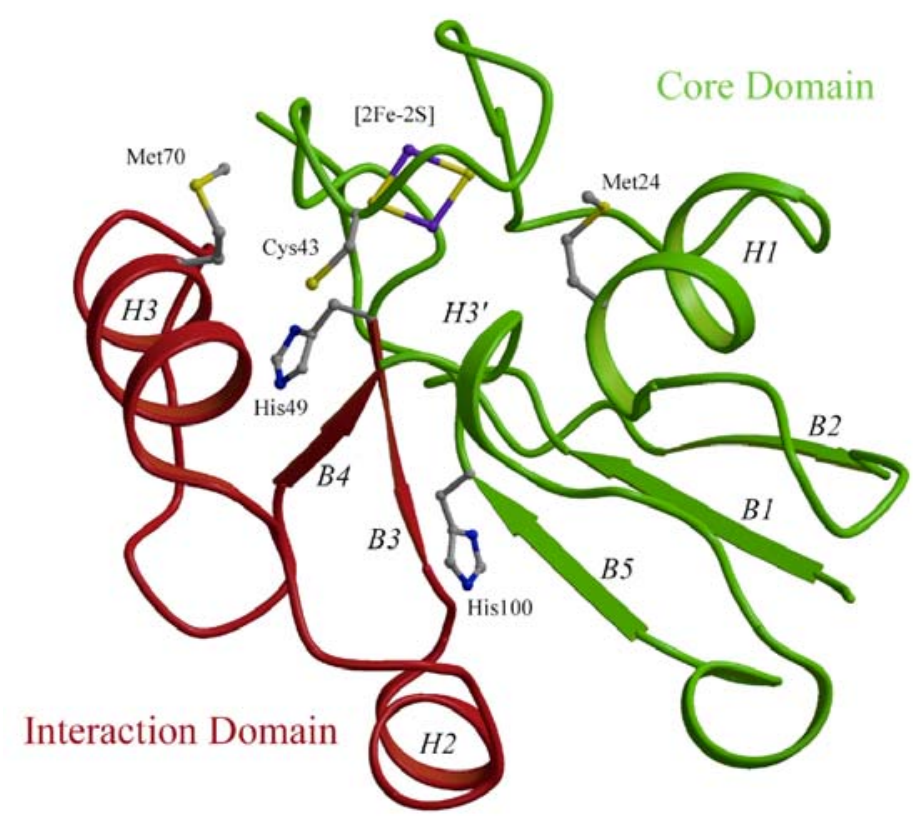

b

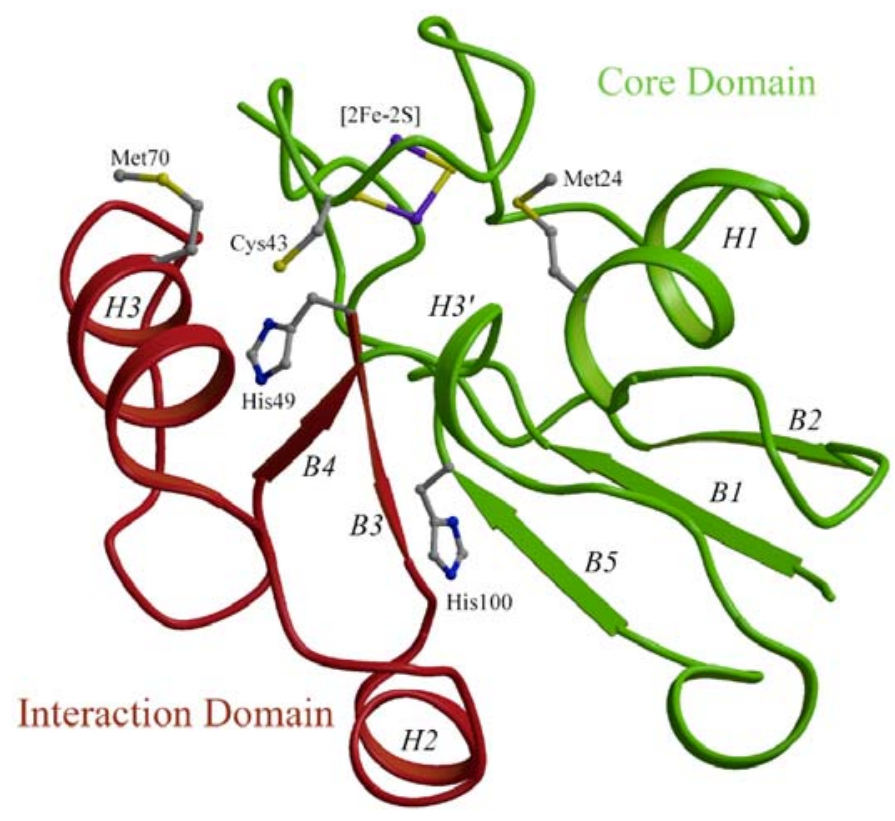

Figure 3 


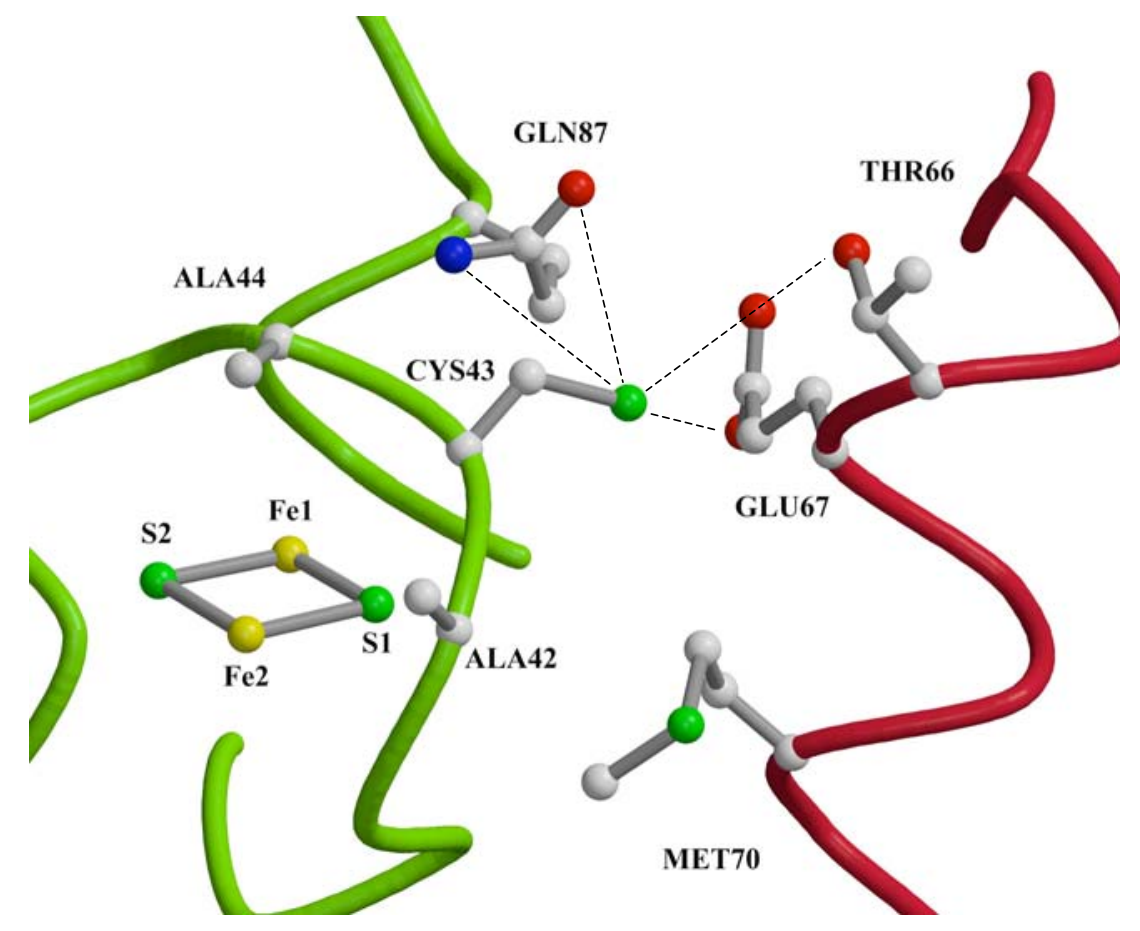

Figure 4 

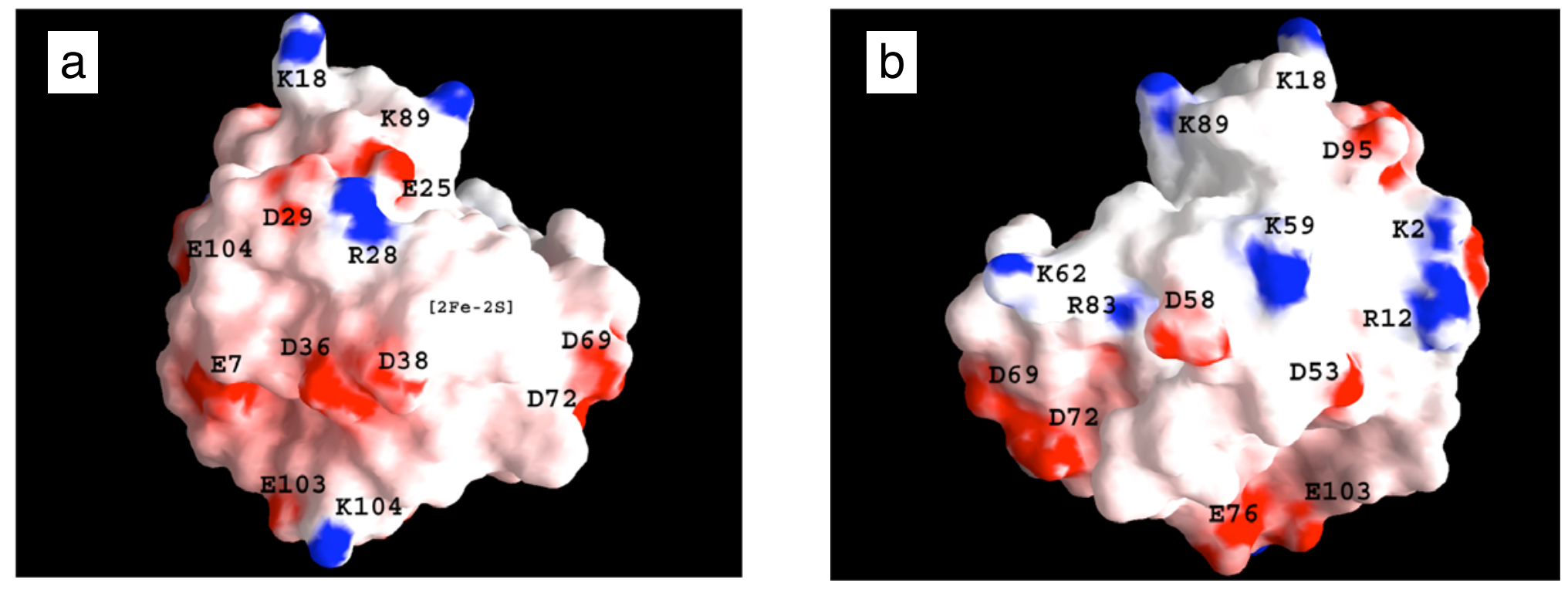

Figure 5 


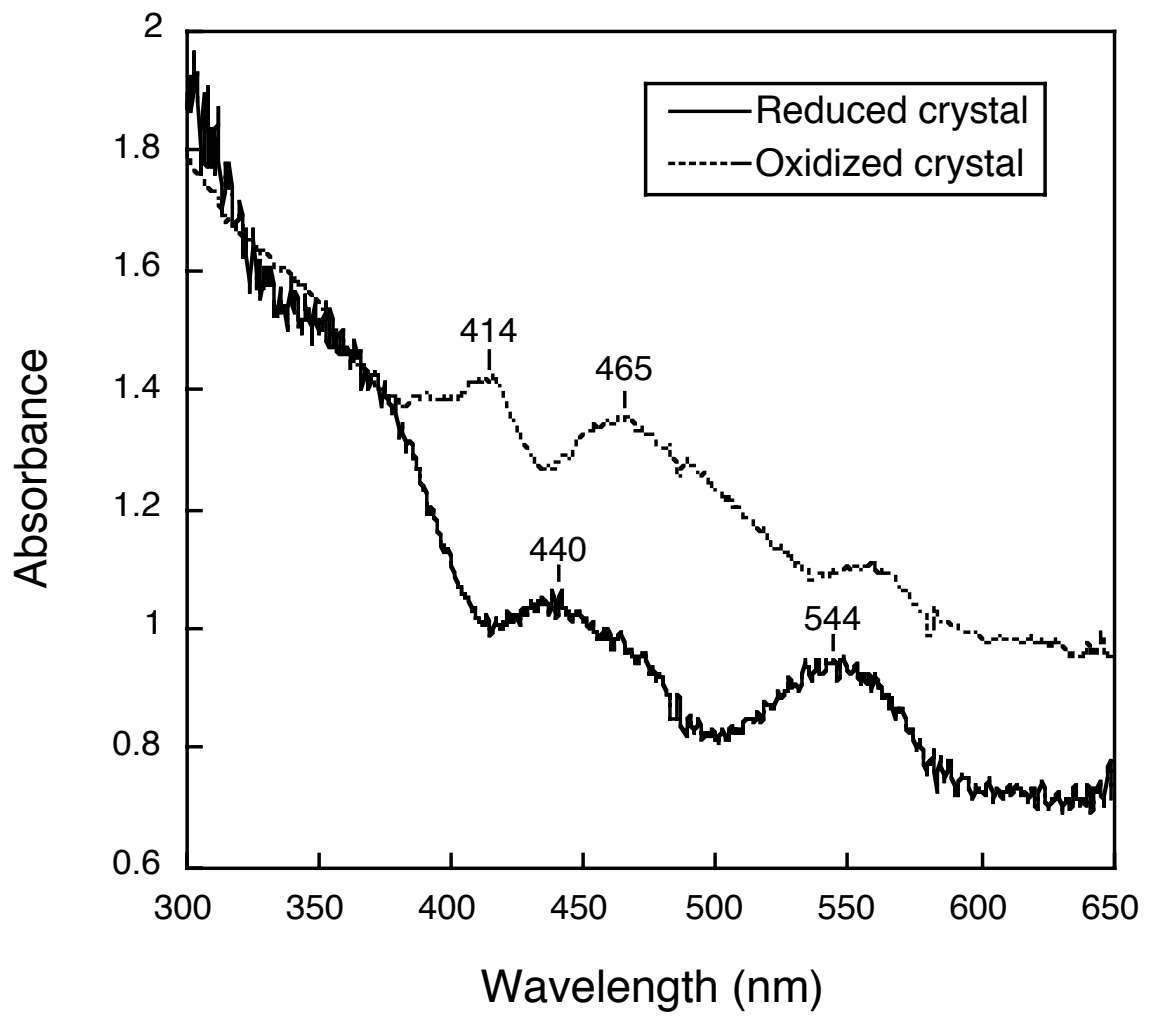

Figure 6 
a

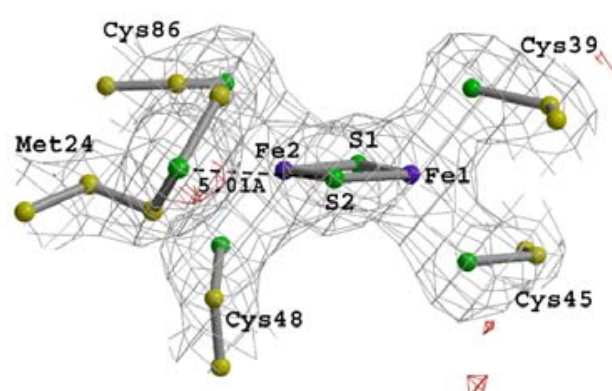

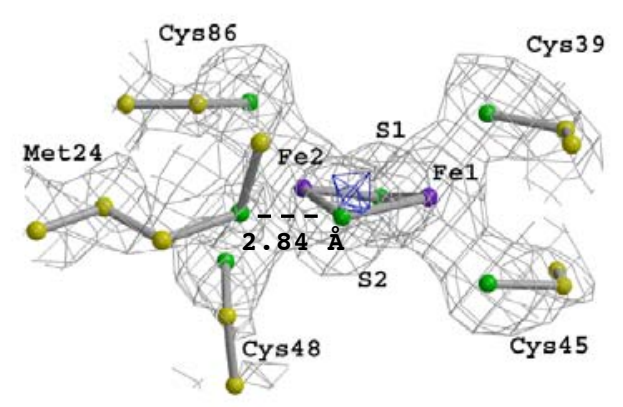

C

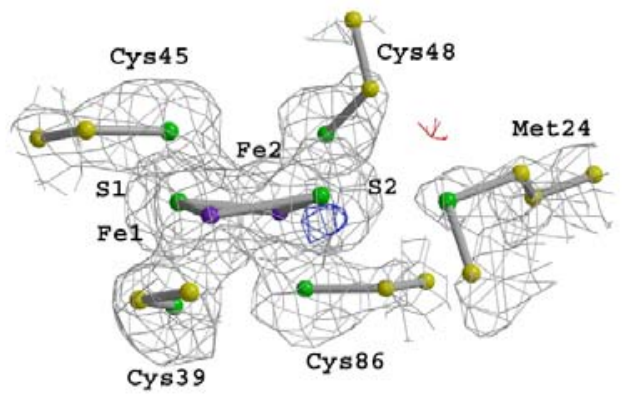

Figure 7 